\title{
ARTICLE \\ Bone morphogenetic protein 6 (BMP-6) modulates lung function, pulmonary iron levels and cigarette smoke-induced inflammation
}

\author{
F. M. Verhamme ${ }^{1}$, E. G. De Smet ${ }^{1}$, W. Van Hooste ${ }^{1}$, J. Delanghe ${ }^{2}$, S. E. Verleden ${ }^{3}$, G. F. Joos ${ }^{1}$, G. G. Brusselle ${ }^{1}$ and K. R. Bracke $^{1}$
}

\begin{abstract}
Chronic obstructive pulmonary disease (COPD) is associated with abnormal inflammatory responses and airway wall remodeling, leading to reduced lung function. An association between the bone morphogenetic protein (BMP-6) locus and forced vital capacity has been found in a genome-wide association study. However, the role of BMP-6 in the pathogenesis of COPD remains unknown. The pulmonary expression of BMP- 6 was analyzed in patients with COPD and in cigarette smoke (CS)-exposed mice. We evaluated lung function and histology in BMP-6 KO mice at baseline. We exposed BMP- 6 KO mice to CS for 4 weeks and measured pulmonary inflammation and iron levels. Pulmonary mRNA levels of BMP-6 were decreased in smokers with and without COPD and in CSexposed mice. Importantly, BMP-6 expression was lowest in severe COPD. Accordingly, protein levels of BMP- 6 were decreased in patients with COPD. Lung function measurements demonstrated a decreased compliance and total lung capacity in BMP- 6 KO mice, whereas lung histology was normal. Furthermore, BMP-6 KO mice displayed elevated iron levels and an aggravated CSinduced inflammatory response. These results suggest that BMP-6 is important for normal lung function and that downregulation of BMP-6-as observed in patients with COPD—contributes to pulmonary inflammation after CS exposure.
\end{abstract}

Mucosal Immunology (2019) 12:340-351; https://doi.org/10.1038/s41385-018-0116-2

\section{INTRODUCTION}

Chronic obstructive pulmonary disease (COPD) is characterized by a progressive and not fully reversible airflow limitation that is associated with an enhanced chronic inflammatory response in the airways and the lung. The major risk factor for COPD is tobacco smoking. Pathology of COPD includes obstruction of the small airways (obstructive bronchiolitis) and destruction of lung parenchyma (emphysema). The diagnosis of COPD is made using spirometry. A ratio of the forced expiratory volume in $1 \mathrm{~s}\left(\mathrm{FEV}_{1}\right)$ to the forced vital capacity (FVC) below 0.70 determines the presence of airflow limitation.

COPD results from a complex interplay between genetic susceptibility and environmental exposures. The genetics underlying COPD are currently unknown, although recent studies have identified interesting genetic loci associated with impaired lung function. ${ }^{2,3}$ In a recent meta-analysis of genome-wide association studies by the CHARGE and SpiroMeta consortia, six new loci were identified that were associated with FVC, including the gene encoding bone morphogenetic protein (BMP)- $6 .^{2}$

BMP- 6 is a member of the transforming growth factor (TGF)- $\beta$ superfamily, which includes TGF- $\beta$ s, activins, BMPs and growth differentiation factors. ${ }^{4}$ The BMP subfamily was initially identified as a family of proteins that induce ectopic cartilage and bone formation, but during the last years, data have accumulated demonstrating the involvement of BMPs in development and homeostasis in various organs. ${ }^{5,6}$ BMP-6 is essential for iron homeostasis, as it is an important regulator of hepcidin, a hormone that controls iron export. ${ }^{7,8}$ An increased iron sequestration has been observed in macrophages of patients with COPD, which correlated positively with emphysema severity, suggesting that iron dysregulation might contribute to oxidative stress. ${ }^{9}$ Whether BMP- 6 is simply a nonspecific bystander or whether BMP-6 actively contributes to disease pathology remains to be elucidated.

We hypothesized that BMP-6 contributes to the pathogenesis of COPD by modulating lung function, pulmonary inflammation, and iron levels. First, we determined the expression of BMP- 6 in the lungs of smokers and patients with COPD and in the lungs of mice exposed to $\mathrm{CS} .{ }^{10}$ Next, lung function, morphometry, and histology of BMP-6 KO mice versus WT animals were assessed under basal conditions. Finally, we exposed BMP- 6 KO mice and control littermates to CS for 4 weeks. We analyzed the inflammatory responses in both bronchoalveolar lavage (BAL) and lung tissue and studied the effect of BMP-6 deficiency on iron levels and lipid peroxidation.

\section{RESULTS}

BMP-6 expression and localization in lungs of patients with COPD To characterize the expression of BMP-6 in human lung tissue, we extracted mRNA from lung tissue of 84 subjects (16 neversmokers, 24 smokers without airflow limitation, 30 patients with

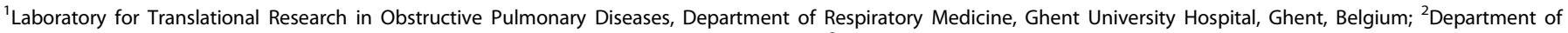

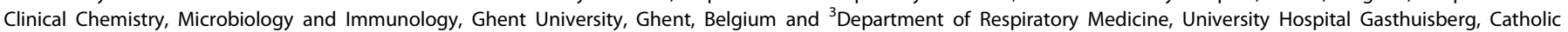
University of Leuven, Leuven, Belgium

Correspondence: F. M. Verhamme (fien.verhamme@UGent.be)
}

Received: 22 December 2017 Revised: 16 October 2018 Accepted: 20 November 2018

Published online: 12 December 2018 
Bone morphogenetic protein 6 (BMP-6) modulates lung function, pulmonary...

Table 1. Characteristics of study subjects for lung mRNA analysis (by qRT-PCR)

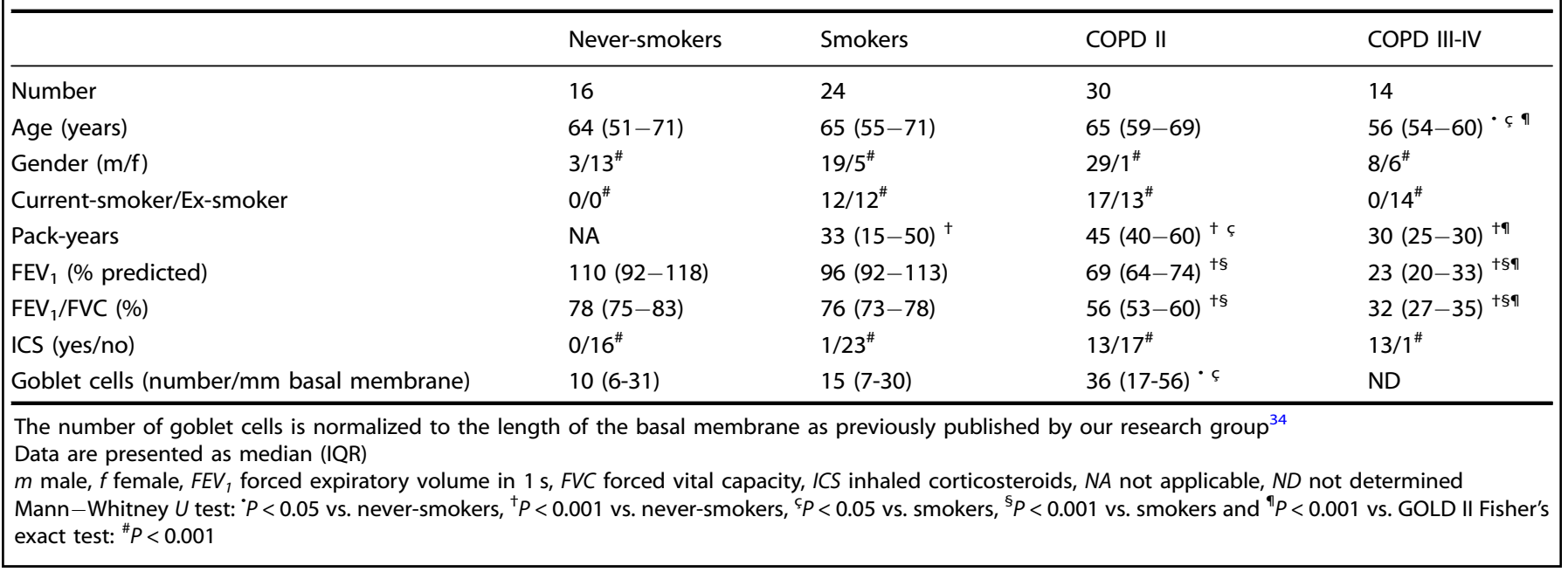

COPD GOLD II and 14 patients with COPD GOLD III-IV). The demographic and clinical characteristics of the different study groups are summarized in Table 1. The mRNA levels of BMP-6 were significantly lower in smokers without COPD and patients with COPD compared to never-smokers. Moreover, the BMP-6 mRNA expression was significantly lower in severe COPD compared to smokers without COPD (Fig. 1a). We found a significant positive correlation between BMP-6 mRNA levels and $\mathrm{FEV}_{1}$ and $\mathrm{FEV}_{1} / \mathrm{FVC}$ values (Fig. 1b, c). The number of goblet cells was significantly higher in patients with COPD GOLD II compared to never-smokers and smokers (Table 1) and correlated negatively with BMP-6 mRNA expression in lung tissue (Fig. 1d). We have performed immunohistochemical staining for BMP-6 on lung tissue of 8 never-smokers, 16 smokers, and 16 patients with COPD GOLD II. The patient characteristics are summarized in Table 2. Figure 1 shows representative photomicrographs of lung sections of never-smokers (E), smokers without COPD (F) and patients with COPD GOLD II (G). We observed positive staining for BMP-6 in airway smooth muscle cells, endothelial cells, and pulmonary macrophages, as well as a weak staining in airway epithelial cells (Figure S1). Using imaging analysis software, we quantified the BMP-6-positive staining in the airway smooth muscle cell layer. We could not find a significant difference between patients with COPD and control groups (Fig. 1h). Additionally, we have analyzed BMP-6 protein levels by western blot on lung homogenates of five never-smokers, five smokers, and five patients with COPD GOLD II (subgroup of population for mRNA analysis). Representative blots can be found in Fig. 1i. BMP-6 protein levels were significantly lower in lung tissue of patients with COPD GOLD II compared to never-smokers and smokers (Fig. 1j).

BMP-6 expression and localization in lungs of CS-exposed mice The effect of CS on the pulmonary expression of BMP- 6 was determined in murine lung tissue by quantitative RT-PCR and immunohistochemistry. mRNA expression of $B M P-6$ was significantly decreased in lung tissue of mice exposed to CS for 24 weeks, compared with air-exposed controls (Fig. 2a). Accordingly, the expression of $I d 1$ and hepcidin, two target genes of BMP-6 signaling, was also reduced in mice exposed to CS (Fig. 2b, c). Immunohistochemistry on murine lung tissue demonstrated BMP-6 staining in airway smooth muscle cells (Fig. 2d, f), endothelial cells (Fig. 2g), and pulmonary macrophages, similar to our observations in human lung tissue. Figure $2 \mathrm{~d}$, e shows representative lung sections stained for BMP-6 in air- and CS-exposed mice.
Effect of BMP-6 deficiency on lung function and histology

We assessed the pulmonary function of WT and BMP-6 KO mice at basal level by using the forced oscillation technique (FlexiVent System). While the dynamic resistance was not different between WT and BMP-6 KO mice, the dynamic elasticity and tissue damping were significantly increased in BMP-6 KO mice. The latter parameter is used to assess tissue resistance. The dynamic compliance was decreased (Fig. $3 a-d$ ). In addition, both the tissue and static elasticity were significantly higher in BMP-6 KO mice, compared to WT mice (Fig. 3e, f). A significantly decreased total lung capacity was registered in BMP-6 KO mice (Fig. 3g). Figure 3h shows representative pressure-volume curves for WT (in blue) and BMP- $6 \mathrm{KO}$ (in red) mice, demonstrating an important shift in BMP-6 KO mice.

To verify whether BMP-6 KO mice have underlying lung structure abnormalities, we have examined the lung histology of adult BMP-6 KO mice ( 30 weeks old) by examining and analyzing $\mathrm{H} \& \mathrm{E}-$, collagen-, fibronectin- or a-SMA-stained lung sections. The deposition of collagen, fibronectin, and a-SMA in the airway wall was similar between BMP-6 KO and WT mice (Fig. $4 \mathrm{a}-\mathrm{c}$ ). Furthermore, morphometric analysis using mean linear intercept revealed no difference between BMP-6 KO and WT mice (Fig. 4d). The wet-to-dry weight of lung tissue, a measure for the water content, and lung volume were not different between the two genotypes (Figure S2).

Pulmonary inflammation is increased in BMP-6 KO mice after 4 weeks CS exposure

The role of BMP-6 in CS-induced pulmonary inflammation was evaluated by exposing BMP- 6 KO and control WT mice to CS for 4 weeks. Exposure to CS significantly increased the absolute numbers of total cells, macrophages, neutrophils, monocytes, and $\mathrm{T}$ lymphocytes in the bronchoalveolar lavage (BAL) fluid of both WT and BMP-6 KO mice (Fig. 5a-f). Remarkably, the CS-induced increase in total cells, macrophages, neutrophils, monocytes, and $\mathrm{CD}^{+}{ }^{+} \mathrm{T}$ cells was significantly aggravated in BMP-6 KO mice, compared to control littermates (Fig. $5 a-e)$. In contrast, the numbers of $\mathrm{CD}^{+} \mathrm{T}$ cells were not different between the WT and BMP-6 KO mice (Fig. 5f).

In lung homogenates, CS exposure significantly increased macrophages, $\mathrm{CD} 11 \mathrm{~b}^{+}$dendritic cells (DCs) and $\mathrm{CD} 69^{+} \mathrm{CD} 8^{+} \mathrm{T}$ lymphocytes in WT mice (Fig. 6a, b, d). CS-exposed BMP-6 KO mice displayed higher numbers of $\mathrm{CD} 11 \mathrm{~b}^{+} \mathrm{DCs}$ and $\mathrm{CD}^{+} 9^{+} \mathrm{CD} 4^{+} \mathrm{T}$ lymphocytes, compared to the CS-exposed control mice (Fig. 6b, c), whereas the other cell types were not different between the two mouse strains (Fig. 6a and d). 

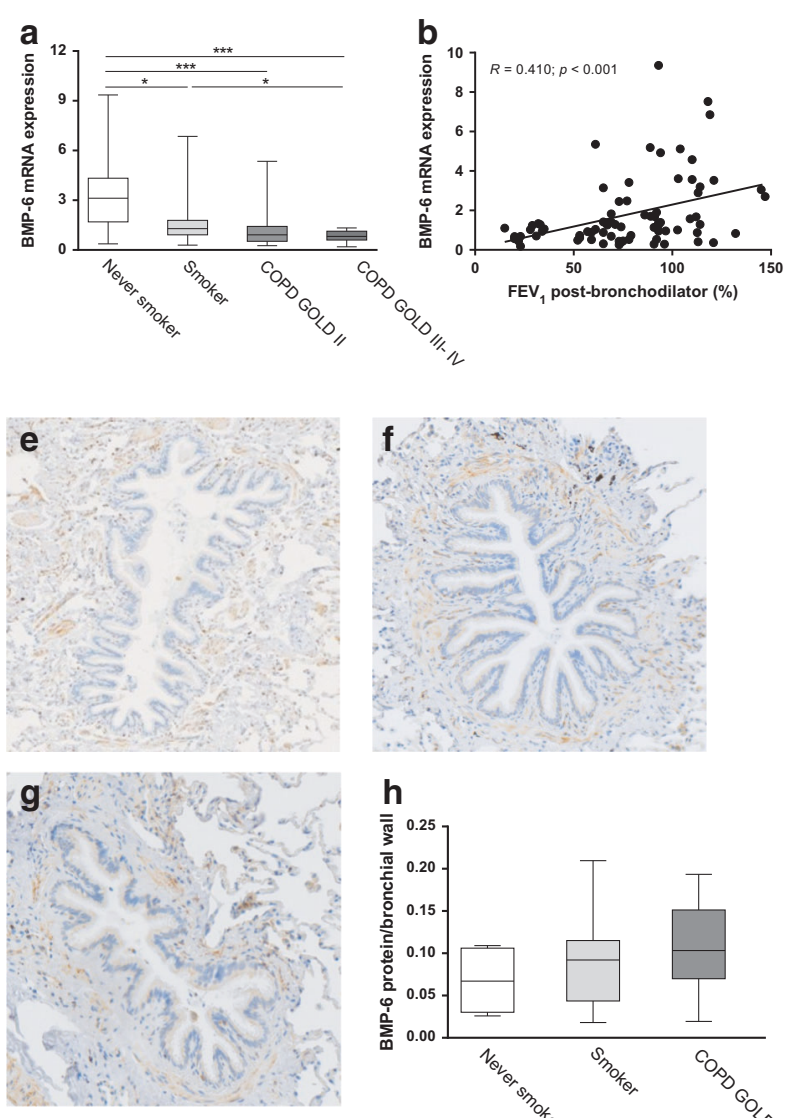
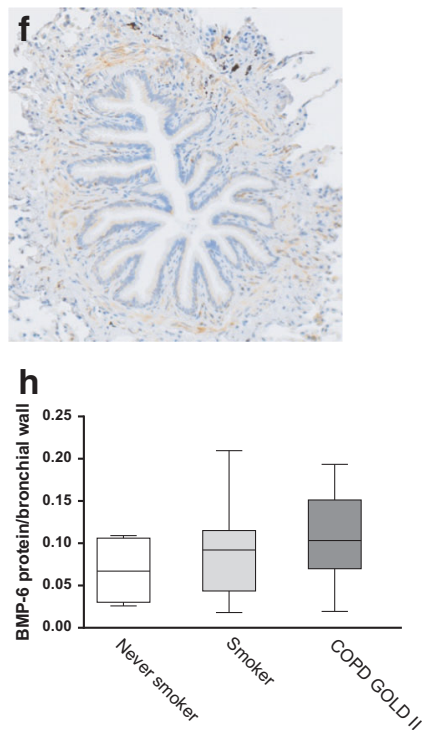
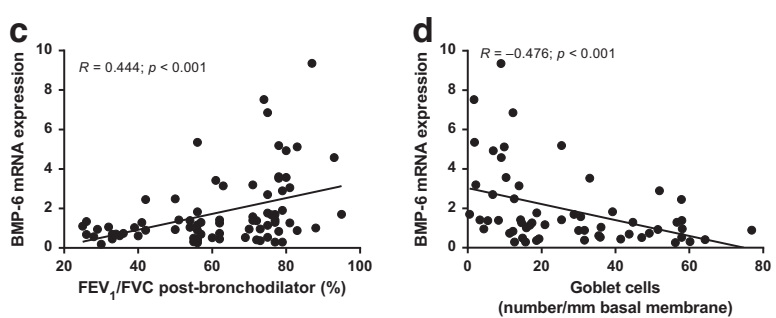

i
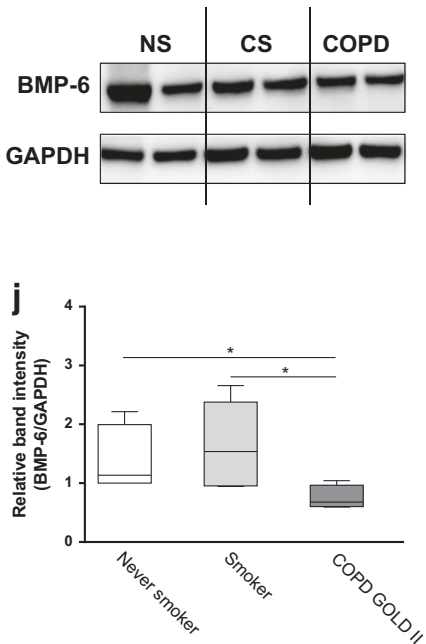

Fig. 1 Pulmonary mRNA and protein expression of BMP-6 in human subjects. mRNA levels of BMP-6 (a) in lung of never-smokers ( $n=16)$, smokers without airflow limitation $(n=24)$, patients with COPD GOLD II $(n=30)$ and patients with COPD GOLD III-IV $(n=14)$, as measured by qRT-PCR. mRNA levels were corrected using a calculated normalization factor based on mRNA expression of three reference genes (GAPDH, $P P I A, H P R T-1)$. Data are expressed as box-and whisker plots $\left({ }^{*} P<0.05\right.$ and $\left.{ }^{* * *} P<0.001\right)$. Nonparametric correlation analysis (Spearman) of the $B M P-6$ mRNA levels with lung function parameters such as post-bronchodilator values of forced expiratory volume in $1 \mathrm{~s}\left(\mathrm{FEV} \mathrm{V}_{1}\right)(\mathbf{b})$ and ratio of $\mathrm{FEV}_{1}$ to forced vital capacity (FEV $/ \mathrm{FVC}$ ) (c) and with the number of PAS ${ }^{+}$goblet cells per millimeter of basal membrane (d). Representative images of immunohistochemical staining for BMP-6 in the airway smooth muscle cell layer of a never-smoker (e), a smoker without airflow limitation (f) and a patient with COPD GOLD II (g). Original magnification $\times 200$. $\mathbf{h}$ Quantification of BMP-6 protein expression in the airway smooth muscle cell layer of never-smokers $(n=8)$, smokers without airflow limitation $(n=16)$ and patients with COPD GOLD II $(n=16)$. Results are expressed as the smooth muscle area positive for BMP- 6 normalized to the complete bronchial wall. $\mathbf{i}$, $\mathbf{j}$ Western blot analysis of BMP- 6 on lung tissue. i Representative blots of BMP- 6 and GAPDH as a loading control are shown. j Densitometric analysis of the western blot of five never-smokers, five smokers without airflow limitation and five patients with COPD (GOLD II)

Table 2. Characteristics of study subjects for immunohistochemical analysis of BMP-6

\begin{tabular}{|c|c|c|c|}
\hline & Never-smokers & Smokers & COPD II \\
\hline Number & 8 & 16 & 16 \\
\hline Age (years) & $65(63-78)$ & $65(56-68)$ & $68(63-69)$ \\
\hline Gender $(\mathrm{m} / \mathrm{f})$ & $3 / 5^{\circ}$ & $13 / 3^{\circ}$ & $13 / 3^{\circ}$ \\
\hline $\begin{array}{l}\text { Current-smoker/Ex- } \\
\text { smoker }\end{array}$ & $0 / 0^{\circ}$ & $8 / 8^{\circ}$ & $8 / 8^{\circ}$ \\
\hline Pack-years & NA & $30(20-50)^{\dagger}$ & $44(34-56)^{\dagger}$ \\
\hline $\mathrm{FEV}_{1}$ (\% predicted) & $96(89-102)$ & $99(91-117)$ & $69(61-77)^{+\S}$ \\
\hline $\mathrm{FEV}_{1} / \mathrm{FVC}(\%)$ & $81(73-93)$ & $77(72-81)$ & $56(49-63)^{\dagger \S}$ \\
\hline ICS (yes/no) & $1 / 7^{\#}$ & $0 / 16^{\#}$ & $9 / 7^{\#}$ \\
\hline
\end{tabular}

Data are presented as median (IQR)

$m$ male, $f$ female, FEV 1 forced expiratory volume in $1 \mathrm{~s}, F V C$ forced vital capacity, ICS inhaled corticosteroids, NA not applicable

Mann-Whitney $U$ test: ${ }^{\dagger} P<0.001$ vs. never-smokers and ${ }^{\S} P<0.001$ vs. smokers

Fisher's exact test: $P<0.05$ and ${ }^{\#} P<0.001$
Effect of BMP-6 deficiency on cytokine/chemokine levels after 4 weeks of CS exposure

Because we observed an increased inflammatory cell recruitment in BMP-6 KO mice upon CS exposure, we measured the pulmonary mRNA expression of the chemokines CCL2 and CXCL1, which attract monocytes and neutrophils, respectively. While CS exposure had no influence on the expression in WT mice, the mRNA levels of CCL2 and CXCL1 were significantly higher in CSexposed BMP-6 KO mice, compared to both air-exposed BMP-6 KO mice and CS-exposed WT mice (Fig. 7a, b). At protein level, we found a similar trend for $C C L 2$ in the BAL fluid. CCL2 was significantly elevated in BAL fluid after CS exposure and a higher concentration of CCL2 was found in BMP- $6 \mathrm{KO}$ mice, regardless of the exposure, compared to WT mice. (Fig. 7c). Furthermore, the CS-induced increase in protein levels of TGF- $\beta 1$ was significantly aggravated in BMP-6 KO mice (Fig. 7d).

BMP-6 deficiency results in increased pulmonary iron deposition BMP-6 deficiency was significantly associated with increased iron levels in serum and lung homogenates (Fig. 8a, b). CS increased iron concentration in serum in WT mice, but decreased iron levels in BMP-6 KO mice (Fig. 8a). Prussian Blue staining confirmed the 
a

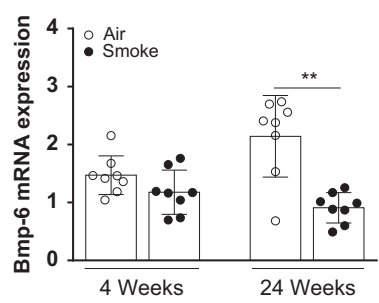

b

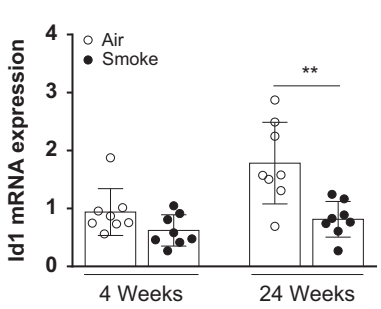

C

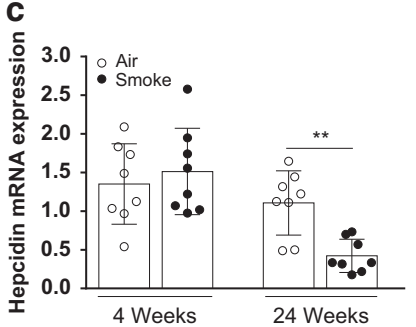

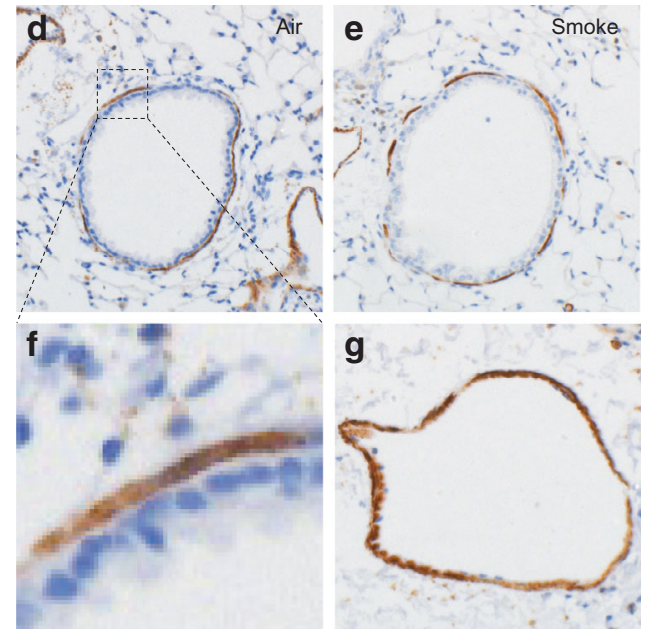

Fig. 2 Pulmonary mRNA expression and localization of BMP-6 in cigarette smoke-exposed C57BL/6 mice. mRNA levels of Bmp-6 (a), Id1 (b), and hepcidin (c) in lung of C57BL/6 mice exposed to CS for 4 and 24 weeks, as measured by qRT-PCR. d-g Representative images of BMP-6stained lung sections of air- and CS-exposed mice. Detail on airway smooth muscle cells in (f). Original magnification $\times 200$. Data are expressed as mean \pm SEM $\left(n=8-10\right.$ animals/group; $\left.{ }^{* *} P<0.01\right)$

elevated iron deposition in lungs of BMP-6 KO mice (Fig. 8e, f). The blue staining was mainly present in the smooth muscle cell layer surrounding the airway (indicated by arrows). WT mice had almost no positive staining for iron in the lung tissue (Fig. $8 c$, d). Iron levels in the BAL fluid could not be detected. Additionally, we determined the concentration of thiobarbituric acid reactive substances (TBARS) in lung homogenates of CS-exposed WT and BMP-6 KO mice as an indicator for the relative lipid peroxide content. We could not find an effect of CS exposure on the TBARS levels. The TBARS levels tended to be higher in BMP-6 KO mice, but this did not reach statistical significance (Fig. 8g). Finally, we performed a terminal deoxynucleotidyl transferase dUTP nick end labeling (TUNEL) assay on lung sections to detect apoptotic cell death. Figure S3 shows representative images of the four groups, including a negative control. We found no obvious differences in TUNEL staining between the different experimental groups.

\section{DISCUSSION}

We reveal decreased mRNA expression of BMP-6 in the lungs of patients with COPD and CS-exposed mice. BMP-6 levels were inversely correlated with disease severity. Accordingly, protein levels of BMP-6 were found to be lower in lung tissue of patients with COPD. In lung tissue, BMP-6 protein expression is observed in airway smooth muscle cells, endothelial cells, and pulmonary macrophages. Using in vivo studies with BMP-6 KO and control WT mice, we demonstrate that BMP- 6 deficiency aggravates the pulmonary inflammation after a subacute CS exposure of 4 weeks. Moreover, BMP-6-deficient mice develop massive iron overload in the lungs and have an impaired lung function.

We demonstrated a lower BMP-6 mRNA expression in the lungs of smokers without airflow limitation and patients with COPD compared to never-smokers. Importantly, patients with severe
COPD had the lowest BMP-6 levels, which were also significantly lower than the levels of smokers without airflow limitation. We confirm thus decreased expression of BMP-6 in patients with COPD, as found in a recent gene expression analysis. ${ }^{11}$ Also in the CS-driven murine model of COPD, we revealed decreased levels of BMP-6 at the mRNA level in lung tissue after 24 weeks of CS. In experimental models of fibrosis, both increased and decreased BMP-6 levels were reported in respectively liver and kidney fibrosis models. ${ }^{12,13}$ BMP-6 is also induced in chronic human skin wounds. ${ }^{14}$ Data regarding the expression of BMP-6 in respiratory models are scarce. One study has demonstrated higher BMP-6 levels in an OVA-induced mouse model of allergic asthma. ${ }^{15}$ To fully address whether the BMP-6 pathway is up- or downregulated, activation of downstream mediators and/or target genes, such as phosphorylation of Smad1/5/8 should be investigated.

Next, we determined the localization of BMP- 6 protein in lung tissue of patients with COPD and CS-exposed mice by immunohistochemical staining. Interestingly, airway smooth muscle cells, endothelial cells, and pulmonary macrophages stained positively for BMP-6. This is in agreement with in vitro studies demonstrating that both smooth muscle cells and endothelial cells can express BMP-6. ${ }^{16,17}$ The localization of BMP-6 in these specific cell types makes sense, knowing its regulatory role in endothelial activation and macrophage proliferation. ${ }^{18,19}$ Quantification of immunohistochemical staining in the airway smooth muscle cell layer could not demonstrate decreased BMP-6 protein expression; however, western blot analysis confirmed lower BMP-6 protein levels in total lung tissue of patients with COPD. These results suggest that the overall BMP-6 expression is decreased in COPD, but this is probably compartment-dependent.

Since the BMP-6 locus emerged to be significantly associated with FVC in a genome-wide association study, we analyzed the 

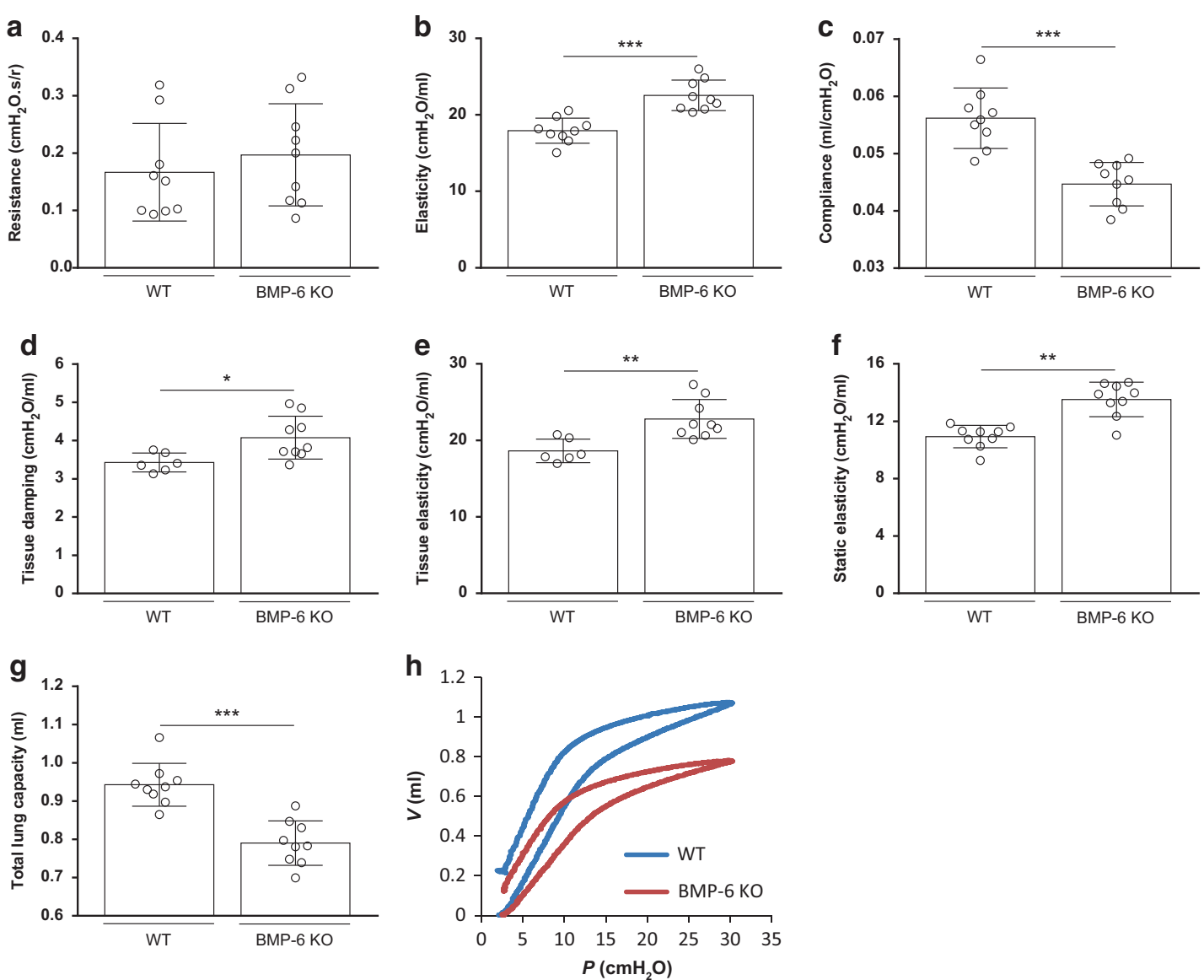

Fig. 3 Effect of BMP-6 deficiency on lung function in mice. Lung function was determined in WT and BMP-6 KO mice under basal conditions. Resistance (a), elasticity (b), and compliance (c) of the entire compartment (airways, tissue, and chest wall). d Tissue damping, related to tissue resistance. e Tissue elasticity. f Static elasticity. g Total lung capacity. Representative PV loops of WT (blue) and BMP-6 KO (red) mice are shown in (h). Data are expressed as mean \pm SEM $\left(n=8-10\right.$ animals/group; $\left.{ }^{*} P<0.05,{ }^{*} P<0.01,{ }^{* *} P<0.001\right)$. Data shown are representative of two independent experiments

lung function of BMP-6 KO mice. ${ }^{2}$ Interestingly, we observed an increased elasticity and decreased TLC, indicating that the lungs of BMP-6 KO mice have an increased stiffness, corresponding to a fibrotic phenotype. Similarly, transient overexpression of gremlin, an extracellular BMP antagonist, in rat lungs resulted in increased elasticity. ${ }^{20}$ Histological analysis of H\&E-, collagen-, fibronectin- or a-SMA-stained lung sections of BMP- $6 \mathrm{KO}$ mice showed no obvious abnormalities. Also, the water content and volume of lungs of BMP-6 KO mice is not different from WT mice. Similar to our results, Slc40a1 ${ }^{\mathrm{C} 26 \mathrm{~S}}$ mice, characterized by increased iron levels, demonstrate restrictive lung disease with decreased total lung capacity, without abnormalities in lung structure. ${ }^{21}$ Thus, it remains unclear what the mechanism is behind the altered lung function in BMP-6 KO mice and more in-depth lung stereological/ physiological analyses of the BMP-6 KO mice are needed.

Exposure of mice to CS for 4 weeks results in pulmonary inflammation characterized by increased numbers of macrophages, neutrophils, DCs, and lymphocytes in BAL fluid. ${ }^{10}$ Most of these manifestations were aggravated in BMP-6 KO mice. Elevated levels of the chemokines CCL2 and CXCL1 can explain the increased recruitment of monocytes and neutrophils to the airways of CS-exposed BMP-6 KO mice. The protective effect of BMP-6 appears to involve modulation of chemokine production, as is also shown in kidney epithelial cells, but BMP-6 can also directly affect inflammatory cells. ${ }^{22}$ Macrophages and $\mathrm{CD}^{+} \mathrm{T}$ cells express functional type II BMP receptors and type I receptors and BMP-6 is able to inhibit cell proliferation of both cell types. ${ }^{18,23}$ Additionally, BMP-6 is able to affect cytokine production as we have observed elevated TGF- $\beta 1$ protein levels in BAL fluid of CSexposed BMP-6 KO mice. Similar observations were made in renal fibrosis in mice. ${ }^{13}$ Additionally, long-term CS exposure experiments of BMP-6 KO mice are warranted to assess structural changes and lung function upon chronic CS exposure as this is not covered in this manuscript.

Finally, BMP-6 KO mice develop iron accumulation in the lungs. With these data, we expand the list of organs (liver, pancreas, heart, and kidney) where massive iron overload is present in BMP$6 \mathrm{KO}$ mice. $^{8}$ We speculate that iron accumulation in the lungs contributes to tissue damage and inflammation via oxidative stress. Indeed, increased concentrations of iron and ferritin, an iron storage protein, have been found in healthy smokers and patients with COPD. ${ }^{24}$ Furthermore, the percentage of iron containing macrophages was positively correlated with COPD and emphysema severity. ${ }^{9}$ This pulmonary iron overload in smokers can have functional implications, considering the tight link between iron, immunity and oxidative stress. ${ }^{25}$ By limiting iron availability for colonizing and/or invading bacteria, the immune system can protect the host from bacterial overgrowth. Hereditary hemochromatosis (Hfe), characterized by systemic iron overload quite similar to BMP-6 deficiency, impairs pulmonary neutrophil recruitment in response to intratracheal instillation of LPS. ${ }^{26}$ However in our experiments, iron levels are not different between air- and CS-exposed mice, so we cannot conclude whether ironmediated oxidative stress also contributes to the higher CSinduced accumulation of inflammatory cells in BMP-6 KO mice. Similarly, lipid peroxidation and apoptosis measurements cannot 
a

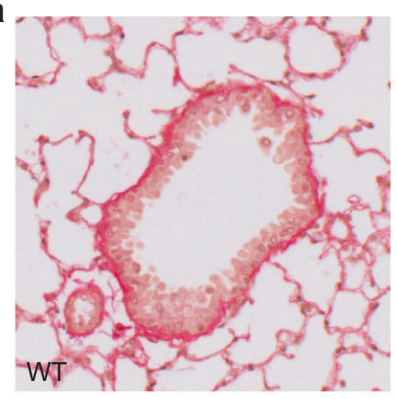

b

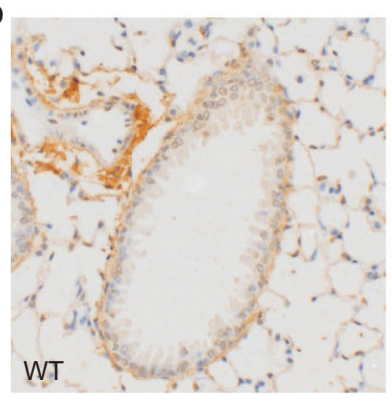

C

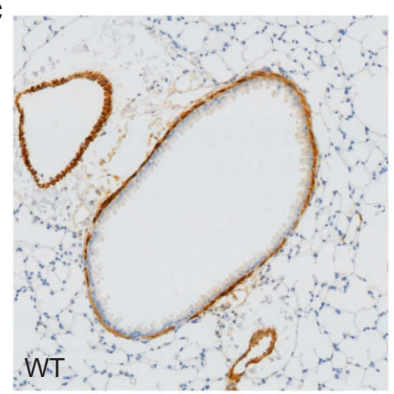

d

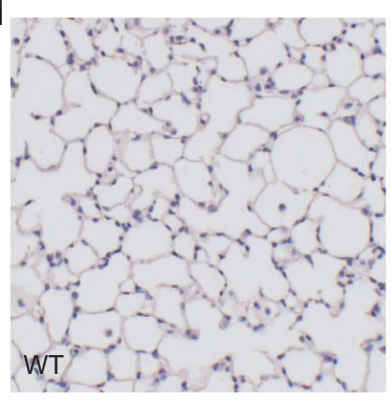

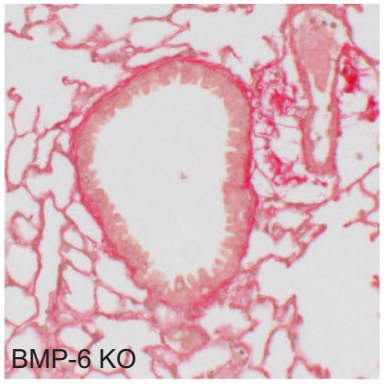
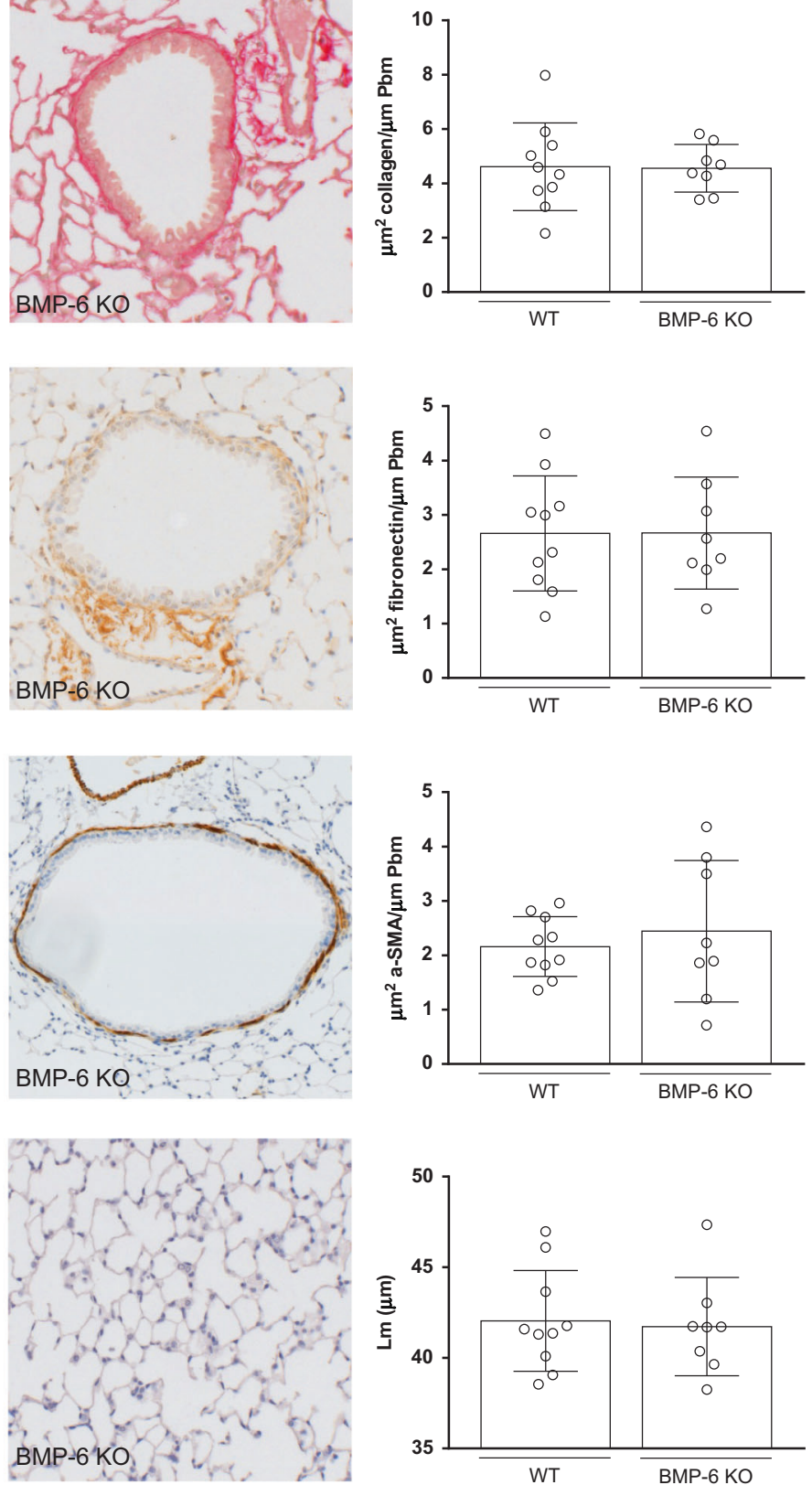

Fig. 4 Effect of BMP-6 deficiency on lung histology in mice. Representative images and quantification of collagen deposition (a), fibronectin deposition (b), and $\alpha$-SMA staining (c) in the airway wall and measurement of mean linear intercept (d) of H\&E-stained lung sections of WT (left panel) and BMP-6 KO mice (right panel). Data are expressed as mean \pm SEM ( $n=8-10$ animals/group)

provide direct evidence that the aggravated effect of BMP-6 deficiency is mediated via oxidative stress or apoptosis. However, it is still plausible that higher iron levels result in a higher occurrence of ferroptosis, an iron-dependent form of regulated necrosis. It has been reported that ferroptosis occurs in the absence of apoptotic markers. ${ }^{27}$

In conclusion, we have shown that BMP-6 mRNA expression is significantly decreased in the lungs of CS-exposed mice and patients with COPD. Also the protein levels of BMP-6 were diminished in lungs of patients with COPD. Deficiency of BMP-6 renders mice more susceptible to the development of CS-induced pulmonary inflammation. Future studies have to further unravel the role of BMP- 6 in structural alterations of the lungs and ironinduced oxidative stress after CS exposure.

\section{MATERIALS AND METHODS}

Human study populations

Lung resection specimens were obtained from 84 patients, of which 70 had surgery for solitary pulmonary tumors (Ghent University Hospital, Ghent, Belgium) and 14 underwent lung transplantation for end-stage COPD (University Hospital Gasthuisberg, Leuven, Belgium). Lung tissue at maximum distance from the pulmonary lesions and without signs of retro-obstructive pneumonia or tumor invasion was collected by a pathologist. None of the patients operated for malignancy were treated with neo-adjuvant chemotherapy.

COPD diagnosis and severity were defined according to the Global Initiative for Chronic Obstructive Lung Disease (GOLD) classification, using preoperative spirometry. ${ }^{1}$ Written informed 

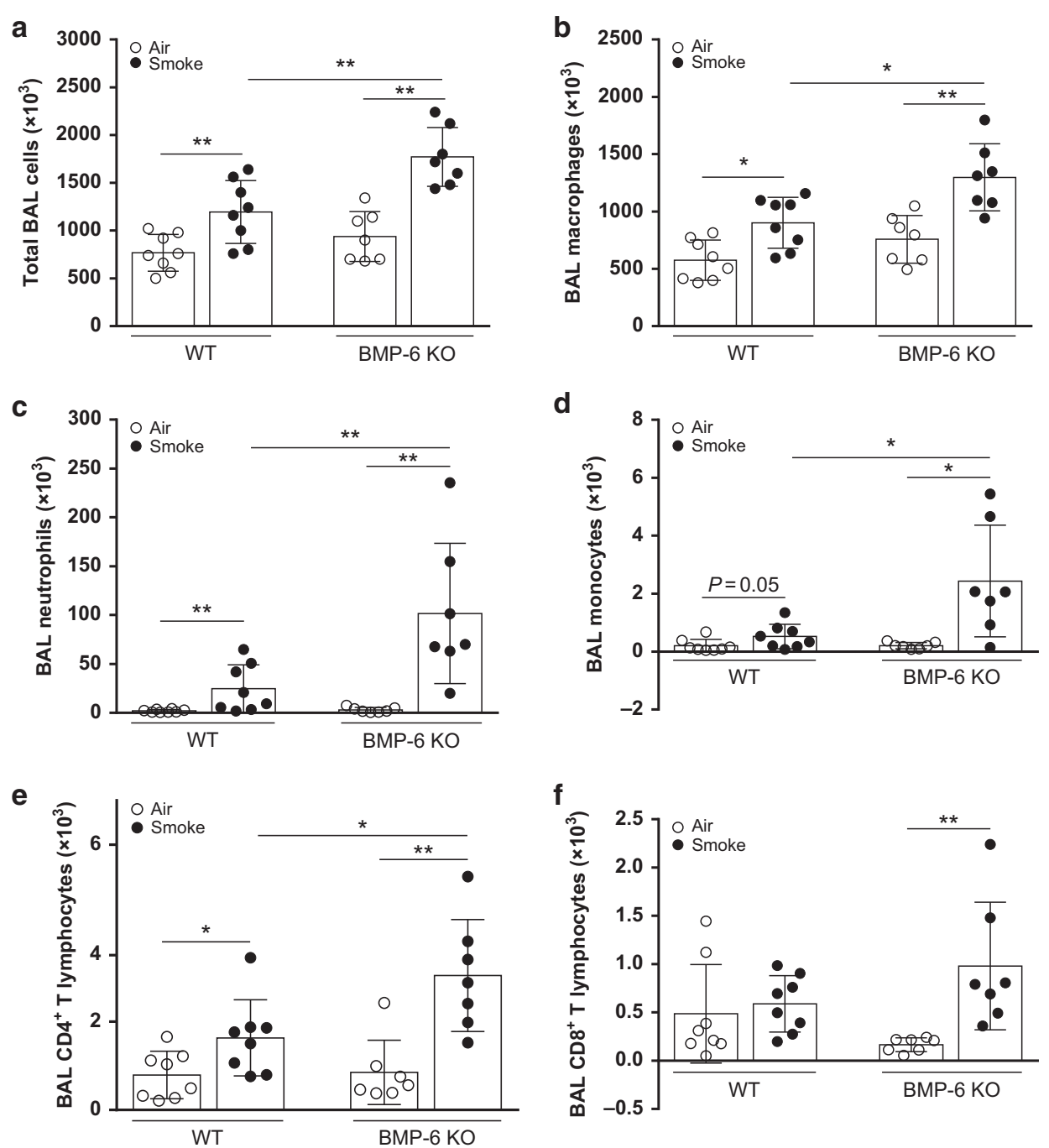

Fig. 5 Effect of CS exposure and BMP-6 deficiency on the total number of bronchoalveolar lavage (BAL) cells and cell subsets in BAL fluid.

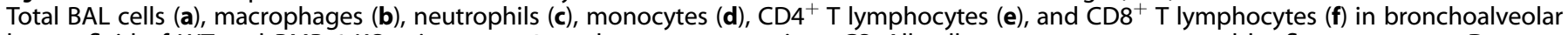
lavage fluid of WT and BMP-6 KO mice upon 4 weeks exposure to air or CS. All cell types were enumerated by flow cytometry. Data are expressed as mean \pm SEM $\left(n=8-12\right.$ animals/group; $\left.{ }^{*} P<0.05,{ }^{*} P<0.01\right)$. Data shown are representative of two independent experiments

consent was obtained from all subjects. This study was approved by the medical ethical committees of the Ghent University Hospital (2011/14) and the University Hospital Gasthuisberg Leuven (S52174).

\section{Animals}

Male C57BI/6Jx129Sv BMP-6 knockout (KO) $\left(B m p 6^{\text {m1rob }}\right)$ mice were mated with female $\mathrm{C} 57 \mathrm{BI} / 6 \mathrm{~J}$ mice in the animal facility at the Faculty of Medicine and Health Sciences, Ghent University (Ghent, Belgium). Genotyping of the offspring was performed on toe DNA by nonquantitative RT-PCR and gel electrophoresis using the following primers: $5^{\prime}$-TCCCCACATCAACGACACCA-3' for sequences located $5^{\prime}$ of exon 2, 5'-CGCTGACAGCCGGA ACACGG-3' for the neo gene and $5^{\prime}$-TCCCCACCACACAGTCCTT G-3' for BMP-6 exon 2. ${ }^{28}$ From the offspring, male BMP-6 KO mice and their WT littermates were used for the present study. C57BL/6J mice were purchased from the Jackson Laboratory (Bar Harbor, ME, USA). All mice were housed in sterilized cages with filter tops under $12 \mathrm{~h}$ light/dark cycle and ad libitum access to food (Pavan, Brussels, Belgium) and chlorinated tap water. All in vivo manipulations were approved by the local Ethics Committee for animal experimentation of the Faculty of Medicine and Health Sciences, Ghent University.
Lung function measurements

Using the Flexivent System (SCIREQ, Montreal, Canada), baseline lung function was examined invasively in tracheostomized anaesthetized mice, as described previously. ${ }^{29}$ Pancuronium bromide $(1 \mathrm{mg} / \mathrm{kg}$ ) (Inresa, Freiburg, Germany), which induces a neuromuscular blockade, was administered via the jugular vein. The mice were ventilated with an average breathing frequency of 150 breaths/minute. Dynamic resistance and elasticity were measured using a "snapshot perturbation" maneuver. The forced oscillation perturbation (Quick-Prime-3 and Prime-8) was applied to assess the tissue damping and elasticity. Pressure-volume (PV) loops were generated to measure the static elasticity and total lung capacity (TLC).

\section{Cigarette smoke exposure}

Mice were exposed to CS, as described previously. ${ }^{10}$ Briefly, animals were exposed whole body to mainstream CS of five cigarettes (Reference Cigarette 3R4F without filter; University of Kentucky) four times a day with 30-min smoke-free intervals, for 4 weeks (subacute) or 24 weeks (chronic). The control groups were exposed to room air. An optimal smoke/air ratio of $1 / 6$ was obtained. Carboxyhemoglobin fractions in the serum of CSexposed mice (4 weeks CS exposure) reached $8.3 \pm 1.4 \%$, 
a

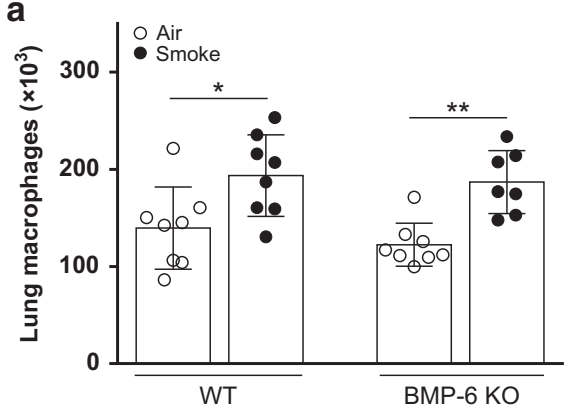

C

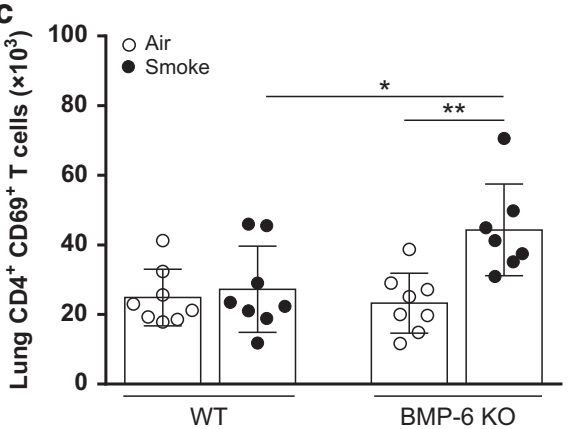

b
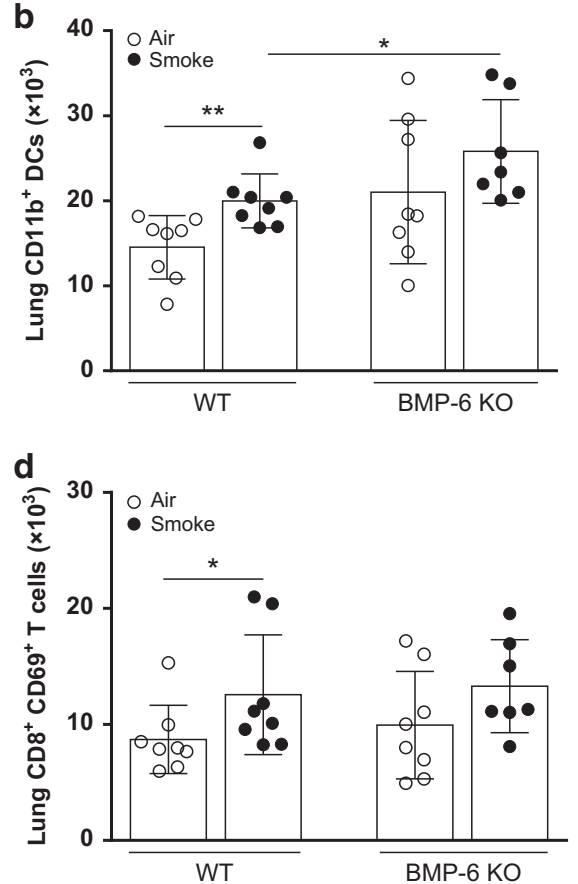

Fig. 6 Effect of CS exposure and BMP-6 deficiency on inflammatory cell numbers in lung tissue. Macrophages (a), CD11 b dendritic cells (DCs) (b), $\mathrm{CD} 4^{+} \mathrm{CD} 69^{+}$T lymphocytes (c), and CD8 ${ }^{+} \mathrm{CD} 69^{+}$T lymphocytes (d) in lung tissue of WT and BMP-6-deficient mice upon 4 weeks exposure to air or CS. All cell types were enumerated by flow cytometry. Data are expressed as mean \pm SEM $\left(n=8-12\right.$ animals/group; ${ }^{*} P<0.05$, ${ }^{* *} P<$ 0.01). Data shown are representative of two independent experiments

compared to $1.0 \pm 0.2 \%$ in air-exposed mice, which is similar to carboxyhemoglobin blood concentrations of human smokers. ${ }^{30}$ Twenty-four hours after the last exposure, mice were sacrificed as described above.

\section{Collection of serum}

Blood was sampled from the orbital sinus and processed for the collection of serum.

\section{Bronchoalveolar lavage}

BAL was performed as previously described. ${ }^{31}$ Briefly, lungs were first lavaged using three times $300 \mu \mathrm{l}$ Hank's Balanced Salt Solution (HBSS), without $\mathrm{Ca}^{2+}$ and $\mathrm{Mg}^{2+}$ and supplemented with $1 \%$ bovine serum albumin (BSA) (for protein measurement), followed by three times $1 \mathrm{ml}$ HBSS without $\mathrm{Ca}^{2+}$ and $\mathrm{Mg}^{2+}$ supplemented with $0.6 \mathrm{mM}$ Ethylenediaminetetraacetic acid (EDTA), via a tracheal cannula. The lavage fractions were pooled. Total BAL counts were obtained using a Bürker chamber.

Lung harvest and preparation of single-cell suspensions

Following BAL, the pulmonary and systemic circulation was rinsed with saline, supplemented with $5 \mathrm{mM}$ EDTA. The left lung was used for histology, as previously described. ${ }^{10}$ The right lung was clamped and removed for RNA extraction (small lobe), preparation of lung homogenates (middle lobe), and preparation of single-cell suspensions (major lobe). For the latter, the lung tissue was thoroughly minced, digested and subjected to red blood cell lyses. After passage through a $50-\mu \mathrm{m}$ cell strainer, cells were counted with a Z2 particle counter (Beckman-Coulter, Inc., Fullerton, CA, USA). ${ }^{10}$

\section{Histology}

To evaluate airway wall remodeling, collagen was stained chemically with Sirius Red (Calbiochem, BadsSohen, Germany). Fibronectin was stained with mouse monoclonal anti-fibronectin (Thermo Scientific), and a-SMA with rabbit polyclonal anti-alpha smooth muscle actin (Abcam). ${ }^{32}$ The amount of collagen, fibronectin, and a-SMA in the airway wall was quantified using the Axiovision software (Zeiss). The area of positive staining was normalized to the length of the basement membrane (Pbm). All airways with a Pbm smaller than $2000 \mu \mathrm{m}$ and cut in reasonable cross sections (defined by a ratio of maximal internal diameter greater than 0.5 ) were included. To quantify emphysema, lung tissues were stained with H\&E (Sigma-Aldrich), after which airspace enlargement was determined by measuring the mean linear intercept $(\mathrm{Lm})$ using ImageJ software. A $100 \times 100 \mu \mathrm{m}$ grid was placed on top of lung sections and each intercept of alveolar wall on a line of the grid was counted. The total length of each line of the grid divided by the number of intercepts results in an average distance between two alveolar walls or the Lm.

Wet-to-dry lung weight ratio and lung volume measurements WT and BMP-6 KO mice (6-8 weeks old) were sacrificed by an intraperitoneal (i.p.) injection of pentobarbital (CEVA-Sanofi, Paris, France). After rinsing of the pulmonary and systemic circulation with saline, supplemented with $5 \mathrm{mM}$ EDTA, the right lung was collected and its weight was measured immediately after excision (wet weight). The lung tissue was then dried in an oven at $37^{\circ} \mathrm{C}$ for $24 \mathrm{~h}$ and re-weighed as dry weight. The weight ratio was calculated by dividing the wet by the dry weight.

After excision of the right lung, the left lung was fixated by infusion of $4 \%$ paraformaldehyde through the tracheal cannula by a continuous release pump. The lungs were collected and total lung volume was determined by the water displacement method.

Flow cytometry

Cells (both BAL and lung single-cell suspensions) were first incubated with FcR blocking antibody (anti-CD16/CD32, clone $2.4 \mathrm{G} 2$ ) to reduce nonspecific binding. Secondly, labeling reactions were performed to identify the macrophages, DCs, inflammatory monocytes, inflammatory neutrophils, and lymphocytes, using the following Abs: FITC-conjugated CD45 (clone 30-F11), PE-conjugated 

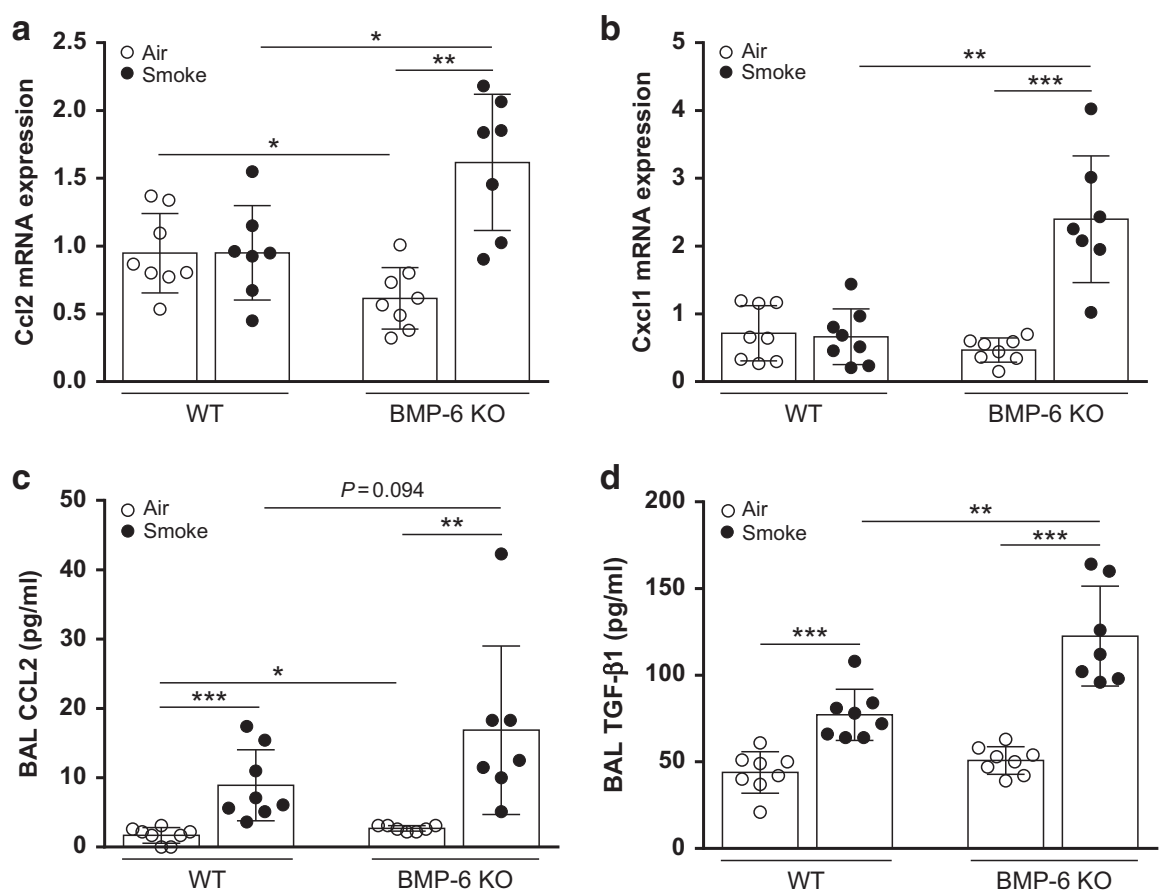

Fig. 7 Effect of CS exposure and BMP-6 deficiency on chemokines/cytokines in lung tissue and BAL supernatants. CCL2 (a) and CXCL1 (b) mRNA expression in lung tissue of WT and BMP-6-deficient mice upon 4 weeks exposure to air or CS. mRNA levels were corrected using a calculated normalization factor based on mRNA expression of three reference genes (GAPDH, TFRC, HPRT-1). Protein levels of CCL2 (c) and TGF- $\beta 1$ (d) in BAL supernatants of WT and BMP-6 KO mice upon 4 weeks exposure to air or CS, as measured by ELISA. Data are expressed as mean \pm SEM $\left(n=8-12\right.$ animals/group; $\left.{ }^{*} P<0.05,{ }^{* *} P<0.01,{ }^{* * *} P<0.001\right)$. Data shown are representative of two independent experiments

Siglec-F (clone E50-2440), APC-conjugated CD11c (clone HL3), Alexa Fluor 700-conjugated Ly6C (clone AL-21), PE-Cy7-conjugated Ly6G (clone 1A8) and PE-conjugated CD69 (H1.2F3) from BD Biosciences (San Diego, CA, USA), Alexa Fluor 700-conjugated CD8 (clone 536.7), APC-Cy7-conjugated MHC-II (I-A/I-E, clone M5/114.15.2), BV421conjugated CD103 (clone 2E7), Pacific Blue-conjugated CD3 (clone 145-2C11) and APC-conjugated CD4 (clone GK1.5) from Biolegend (San Diego, CA, USA) and BV605-conjugated CD11b (clone M1/70) from eBioscience (San Diego, CA, USA). All reactions were performed on ice in FACS-EDTA buffer. After excluding doublets, the $\mathrm{CD}_{4} 5^{+}$cells were retained. First, alveolar macrophages were gated out as Siglec ${ }^{-} \mathrm{F}^{+}$and $\mathrm{CD} 11 \mathrm{c}^{+}$cells. Of the remaining cell population, the DCs were defined as $\mathrm{MHCII}^{\text {hi }}$ and $\mathrm{CD} 11 \mathrm{c}^{\mathrm{hi}}$ with $\mathrm{a}$ subpopulation of $\mathrm{CD} 11 \mathrm{~b}^{+} \mathrm{DCs}\left(\mathrm{CD} 103^{-}\right.$and $\left.\mathrm{CD} 11 \mathrm{~b}^{+}\right)$. After gating out the alveolar macrophages and the DCs, neutrophils were identified as $\mathrm{CD} 11 \mathrm{C}^{-} \mathrm{CD} 11 \mathrm{~b}^{+} \mathrm{Ly}_{6 \mathrm{G}}{ }^{+} \mathrm{Ly} 6 \mathrm{C}^{\text {int }}$ and inflammatory mono-

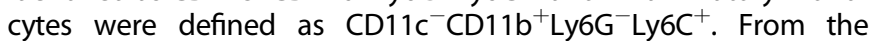
$\mathrm{CD}^{+} 5^{+}$population, $\mathrm{T}$ lymphocytes were characterized as small, $\mathrm{B}_{22}{ }^{-}, \mathrm{MHC}-\mathrm{II}^{-}, \mathrm{CD}^{+}$, which are further separated in $\mathrm{CD}^{+}$and

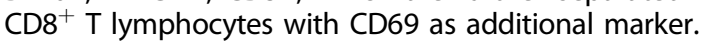

Flow cytometry data acquisition was performed on an LRS FortessaTM flow cytometer running FACSDivaTM software (BD Biosciences). FlowJo Software (Tree Star Inc., Ashland, OR, USA) was used for data analysis.

Preparation of lung tissue homogenate

Human lung tissue specimens and the middle lobe of the right lung (mice) were snap-frozen (in liquid nitrogen) and stored at $-80^{\circ} \mathrm{C}$ until further analysis. The tissues were transferred to tubes containing $1 \mathrm{ml}$ RIPA buffer (Cell Signaling Technology, Danvers, USA) containing Halt ${ }^{\mathrm{TM}}$ Protease Inhibitor Cocktail Kit (Thermo Scientific, Waltham, MA, USA) and homogenized on ice using TissueRuptor (Qiagen, Hilden, Germany). The homogenates were sonicated (four times for $5 \mathrm{~s}$ ) and centrifuged $(14,000 \mathrm{rpm}$ for $10 \mathrm{~min}$ at $4^{\circ} \mathrm{C}$ ) and the middle layer was transferred to microcentrifuge tubes. Total protein concentration was measured using the Pierce ${ }^{T M}$ BCA Protein Assay Kit (Thermo Scientific). Lung tissue homogenates were used undiluted (for WB) or were diluted with RIPA buffer to a final protein concentration of $500 \mu \mathrm{g} / \mathrm{ml}$.

\section{Western blot}

Equal amounts of protein $(30 \mu \mathrm{g})$ were mixed with NuPAGE LDS Sample Buffer (Thermo Scientific) and denatured at $70^{\circ} \mathrm{C}$ for 10 min. After denaturation, NuPAGE Reducing Agent (Thermo Scientific) was added. Next, the samples were separated by SDSPAGE, followed by wet protein transfer to methanol activated Novex ${ }^{\circledR}$ pre-cut polyvinylidene difluoride membranes (Thermo Scientific). The membrane was blocked for $1 \mathrm{~h}$ at room temperature with $5 \%$ nonfat dry milk in TBS/0.2\% Tween-20 (TBST) to prevent nonspecific binding. Then, the membrane was washed (three times for $5 \mathrm{~min}$ ) in TBST followed by incubation with rabbit monoclonal anti-BMP-6 (Abcam) in 5\% BSA in TBST overnight at $4{ }^{\circ} \mathrm{C}$ while shaking. After washing (three times for 5 $\mathrm{min})$, the membrane was incubated with an anti-rabbit horseradish peroxidase (HRP)-conjugated secondary antibody (GE Healthcare) in 5\% nonfat dry milk in TBST for $1 \mathrm{~h}$ at room temperature. The proteins were visualized with SuperSignal ${ }^{\mathrm{TM}}$ West Dura Extended Duration Substrate (Thermo Scientific) and documented by the ChemiDoc Touch Imaging System (Bio-Rad, Hercules, CA, USA). Band quantification was performed in Image Lab (version 3.0, Bio-Rad, Hercules, CA).

\section{ELISA}

CCL2 and TGF- $\beta 1$ protein levels in the BAL fluid were determined by an ELISA kit purchased from R\&D Systems (Abingdon, UK). All ELISAs were performed following the manufacturer's instructions.

BMP-6 immunohistochemistry

To evaluate BMP-6 expression in lung tissue (both human and mice), paraffin-embedded sections were subjected to BMP-6 staining using an anti-BMP-6 antibody (Abcam). Three-micrometer-thick paraffin-embedded sections were cut on 
a
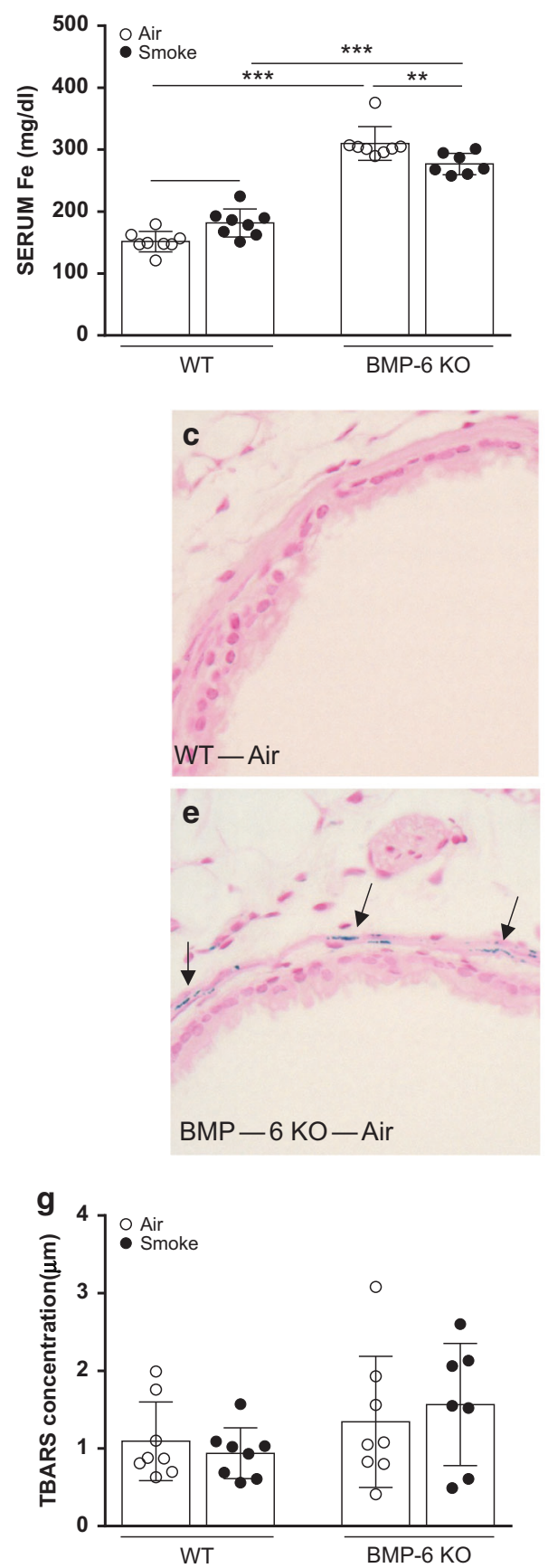

b
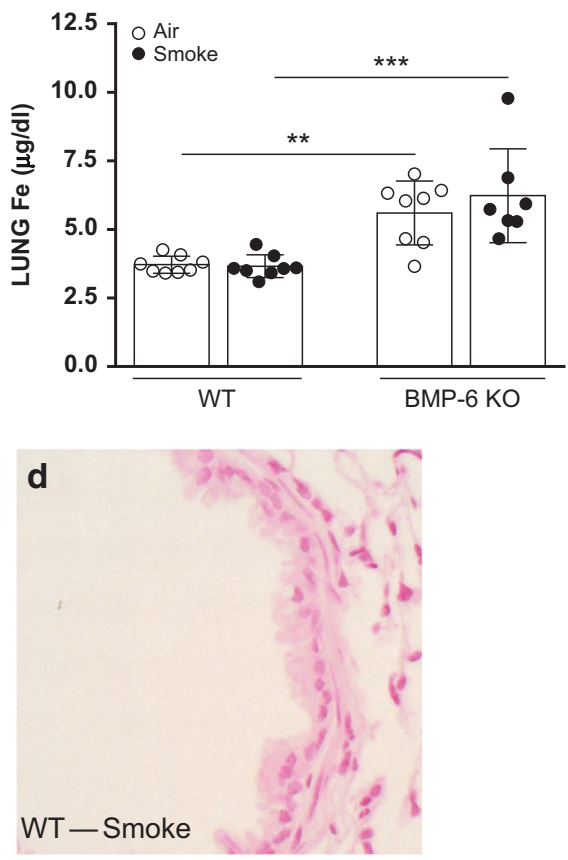

f

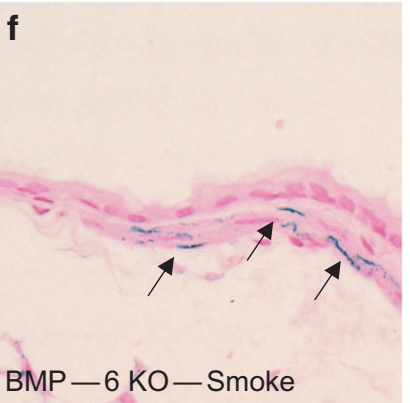

Fig. 8 Effect of CS exposure and BMP-6 deficiency on iron levels in serum and lung tissue. Quantification of the iron concentration in serum (a) and lung homogenates (b) of WT and BMP- 6 KO mice exposed to air or CS for 4 weeks. Data are expressed as mean \pm SEM $(n=8-12$ animals/group; $\left.{ }^{* *} P<0.01,{ }^{* * *} P<0.001\right)$. c-f Representative photomicrographs of the Prussian blue staining on lung sections of WT and BMP-6 $\mathrm{KO}$ mice exposed to air or CS for 4 weeks. Iron deposition is colored in blue and indicated by arrows. Data shown are representative of two independent experiments. g TBARS concentration in lung tissue of WT and BMP-6 KO mice upon 4 weeks exposure to air or CS

poly-L-lysin coated slides. After dewaxing with Ultra Clear (Klinipath, Duiven, The Netherlands) and rehydrations, antigen retrieval was performed using citrate-buffer. After blocking for endogenous peroxidase activity and application of Fc-block, slides were incubated with rabbit monoclonal anti-BMP-6 or isotype rabbit IgG (Abcam) during $24 \mathrm{~h}$, followed by incubation with PowerVision poly-horseradish peroxidase-anti-rabbit (Immunovision Technologies, Burlingame, USA). After rinsing with Phosphate Buffered Saline (PBS) containing 0.3\% Triton X-100, diaminobenzidine substrate (Dako, Glostrup, Denmark) was added for $30 \mathrm{~min}$, sections were rinsed in demineralized water, counterstained with Mayer's hematoxylin (Sigma-Aldrich, St. Louis, USA), dehydrated and mounted in DPX (Klinipath, Duiven, The Netherlands). Photomicrographs were taken using Axiovision software (Zeiss, Oberkochen, Germany). The area with positive BMP-6 staining in airway smooth muscle was quantified using the Axiovision software (Zeiss) and was normalized to the complete bronchial wall. 
RNA extraction and real-time PCR-analysis

Total RNA was extracted from isolated macrophages and from total lung tissue (human and mice) with the miRNeasy Mini kit (Qiagen). cDNA was obtained by the Transcriptor First Strand cDNA synthesis kit (Roche, Basel, Switzerland), following the manufacturer's instructions. Expression of target genes BMP-6, CCL2, CXCL1, Id1, hepcidin and reference genes Glyceraldehyde-3-phosphate dehydrogenase $(G A P D H)$, Hypoxanthine phosphoribosyltransferase-1 (HPRT-1) and Peptidylpropyl isomerase 1 (PPIA) were analyzed using Taqman Gene Expression Assays (Applied Biosystems, Forster City, CA, USA). Real-time PCR reactions were set up in duplicate using diluted cDNA using identical amplification conditions for each of the target and reference genes. A standard curve derived from serial dilutions of a mixture of all samples was included in each run. The amplification conditions consisted of: $10 \mathrm{~min}$ at $95^{\circ} \mathrm{C}$ and 50 cycles of $95^{\circ} \mathrm{C}$ for $10 \mathrm{~s}$ and $60^{\circ} \mathrm{C}$ for $15 \mathrm{~s}$. Amplifications were performed using a LightCycler 480 detection system (Roche). Data were processed using the standard curve method. Expression of target genes was corrected by a normalization factor that was calculated based on the expression of two or three reference genes, using the geNorm applet according to the guidelines and theoretical framework previously described (https://genorm.cmgg.be/). ${ }^{33}$

\section{Quantification of iron concentration}

The iron concentration in lung homogenates and serum was assayed using a ferrozine-based colorimetric method on a Cobas ${ }^{\circledR}$ 8000 analyzer (Roche).

\section{Prussian blue staining}

Prussian Blue or Perls' reaction is used to demonstrate ferric iron on paraffin-embedded sections of mice lung tissue according to the instructions of the supplier (ab150674, Abcam). Photomicrographs were taken using Axiovision software (Zeiss).

\section{TBARS measurement}

Thiobarbituric acid reactive substances (TBARS) levels were determined by an assay kit purchased from R\&D Systems (Abingdon, UK). The assay was performed following the manufacturer's instructions.

Terminal deoxynucleotidyl transferase dUTP nick end labeling (TUNEL) assay

We used a commercially available in situ cell death detection kit (Roche) according to the manufacturer's instructions. Shortly, the sections were deparaffinized and treated with a permeabilization solution that consists of Triton X100 (Sigma), sodium citrate (Fisher BioReagents) and demineralized water. Thereafter the TUNEL reaction mixture was added to the sections for $60 \mathrm{~min}$ at $37^{\circ} \mathrm{C}$ in a humidified box in the dark. The negative controls were incubated with the label solution. After the washing steps, the sections were incubated with 4',6-diamidino-2-phenylindole (DAPI) for $2 \mathrm{~h}$. Finally, the sections were mounted with fluorescence mounting medium (Dako).

Statistical analysis

Statistical analysis was performed with Sigma Stat software (SPSS 23.0, Chicago, IL, USA), using Kruskal-Wallis, Mann-Whitney $U$, Fisher's exact test, and Spearman correlation analysis. Characteristics of the study population are expressed as median and interquartile range. Reported values are expressed as mean \pm SEM. Differences at $P$ values $<0.05$ were considered to be significant $\left({ }^{*} P<0.05,{ }^{*} P<0.01\right.$ and $\left.{ }^{* * *} P<0.001\right)$.

\section{ACKNOWLEDGEMENTS}

The authors would like to thank Greet Barbier, Indra De Borle, Katleen De Saedeleer, Anouck Goethals, and Ann Neesen from the Laboratory for Translational Research in Obstructive Pulmonary Diseases, Department of Respiratory Medicine (Ghent
University Hospital, Ghent, Belgium) for their excellent technical assistance. Furthermore, we thank Elizabeth Robertson (University of Oxford, England, UK) for kindly providing the BMP-6-deficient mice. We also thank Bart Vanaudenaerde and Wim Janssens (Department of Respiratory Medicine, Leuven) for providing us with the explant lungs of patients with severe COPD. The research described in this article was supported by the Concerted Research Action of the Ghent University (BOF/GOA, 01G02714), by the Fund for Scientific Research in Flanders (FWO Vlaanderen) and by the Interuniversity Attraction Poles program (IUAP, P7/30). Part of this work was supported by COST Action BM1201, Developmental Origins of Chronic Lung Disease. F.M.V. is a post-doctoral researcher at the Fund for Scientific Research-Flanders.

\section{AUTHOR CONTRIBUTIONS}

K.R.B., G.G.B., and F.M.V. conceived the project and designed the experiments; K.R.B., F.M.V., E.G.D.S., and W.V.H. conducted the experiments; K.R.B., G.G.B., F.M.V., J.D., S.E.V., and G.F.J. contributed to the data analysis, plotting and interpretation; F.M.V. wrote the manuscript and all authors contributed to the writing and editing of the manuscript.

\section{ADDITIONAL INFORMATION}

The online version of this article (https://doi.org/10.1038/s41385-018-0116-2) contains supplementary material, which is available to authorized users.

Competing interests: The authors declare no competing interests.

\section{REFERENCES}

1. Vogelmeier, C. F. et al. Global strategy for the diagnosis, management, and prevention of chronic obstructive lung disease 2017 report. GOLD executive summary. Am. J. Respir. Crit. Care. Med. 195, 557-582 (2017).

2. Loth, D. W. et al. Genome-wide association analysis identifies six new loci associated with forced vital capacity. Nat. Genet. 46, 669-677 (2014)

3. Soler Artigas, M. et al. Genome-wide association and large-scale follow up identifies 16 new loci influencing lung function. Nat. Genet. 43, 1082-1090 (2011).

4. Kingsley, D. M. The TGF-beta superfamily: new members, new receptors, and new genetic tests of function in different organisms. Genes Dev. 8, 133-146 (1994).

5. Wozney, J. M. et al. Novel regulators of bone formation: molecular clones and activities. Science 242, 1528-1534 (1988).

6. Obradovic Wagner, D. et al. BMPs: from bone to body morphogenetic proteins. Sci. Signal. 3, mr1 (2010).

7. Andriopoulos, B. Jr et al. BMP6 is a key endogenous regulator of hepcidin expression and iron metabolism. Nat. Genet. 41, 482-487 (2009).

8. Meynard, D. et al. Lack of the bone morphogenetic protein BMP6 induces massive iron overload. Nat. Genet. 41, 478-481 (2009).

9. Philippot, Q. et al. Increased Iron Sequestration in Alveolar Macrophages in Chronic Obtructive Pulmonary Disease. PLoS ONE 9, e96285 (2014).

10. D'hulst, A. I., Vermaelen, K. Y., Brusselle, G. G., Joos, G. F. \& Pauwels, R. A. Time course of cigarette smoke-induced pulmonary inflammation in mice. Eur. Respir. J. 26, 204-213 (2005).

11. Ezzie, M. E. et al. Gene expression networks in COPD: microRNA and mRNA regulation. Thorax 67, 122-131 (2012).

12. Arndt, S., et al. Enhanced expression of BMP6 inhibits hepatic fibrosis in nonalcoholic fatty liver disease. Gut 64, 973-981 (2015).

13. Dendooven, A. et al. Loss of endogenous bone morphogenetic protein-6 aggravates renal fibrosis. Am. J. Pathol. 178, 1069-1079 (2011).

14. Kaiser, S. et al. Induction of bone morphogenetic protein-6 in skin wounds. Reepitheliazation and scar formation in BMP-6 overexpressing transgenic mice. J. Invest. Dermatol. 111, 1145-1152 (1998).

15. Rosendahl, A. et al. Activation of bone morphogenetic protein/Smad signaling in bronchial epithelial cells during airway inflammation. Am. J. Respir. Cell Mol. Biol. 27, 160-169 (2002).

16. Zhang, S. et al. Bone morphogenetic proteins induce apoptosis in human pulmonary vascular smooth muscle cells. Am. J. Physiol.-Lung Cell. Mol. Physiol. 285, L740-L754 (2003).

17. Glienke, J. et al. Differential gene expression by endothelial cells in distinct angiogenic states. Eur. J. Biochem. 267, 2820-2830 (2000).

18. Hong, J. $\mathrm{H}$. et al. Effect of bone morphogenetic protein-6 on macrophages. Immunology 128, e442-e450 (2009).

19. Valdimarsdottir, G. et al. Stimulation of Id1 expression by bone morphogenetic protein is sufficient and necessary for bone morphogenetic protein-induced activation of endothelial cells. Circulation 106, 2263-2270 (2002).

20. Farkas, L. et al. Transient overexpression of Gremlin results in epithelial activation and reversible fibrosis in rat lungs. Am. J. Respir. Cell Mol. Biol. 44, 870-878 (2011). 
Bone morphogenetic protein 6 (BMP-6) modulates lung function, pulmonary... FM Verhamme et al.

21. Neves, J. et al. Disruption of the Hepcidin/Ferroportin regulatory system causes pulmonary iron overload and restrictive lung disease. EBioMedicine 20, 230-239 (2017).

22. Gould, S. E., Day, M., Jones, S. S. \& Dorai, H. BMP-7 regulates chemokine, cytokine, and hemodynamic gene expression in proximal tubule cells1. Kidney Int. 61, 51-60 (2002).

23. Sivertsen, E. A. et al. Inhibitory effects and target genes of bone morphogenetic protein 6 in Jurkat TAg cells. Eur. J. Immunol. 37, 2937-2948 (2007).

24. Ghio, A. J. et al. Particulate matter in cigarette smoke alters iron homeostasis to produce a biological effect. Am. J. Respir. Crit. Care. Med. 178, 1130-1138 (2008).

25. Cherayil, B. J. Iron and immunity: immunological consequences of iron deficiency and overload. Arch. Immunol. Ther. Exp. (Warsz.) 58, 407-415 (2010).

26. Benesova, K. et al. Hfe deficiency impairs pulmonary neutrophil recruitment in response to inflammation. PLOS ONE 7, e39363 (2012).

27. Dixon, S. J. et al. Ferroptosis: an iron-dependent form of nonapoptotic cell death. Cell 149, 1060-1072 (2012).

28. Solloway, M. J. et al. Mice lacking Bmp6 function. Dev. Genet. 22, 321-339 (1998).
29. Seys, L. J. et al. Airway surface dehydration aggravates cigarette smoke-induced hallmarks of COPD in mice. PLOS ONE 10, e0129897 (2015).

30. Macdonald, G. et al. Reduction of carboxyhaemoglobin levels in the venous blood of cigarette smokers following the administration of carbogen. Radiother. Oncol. 73, 367-371 (2004).

31. Bracke, K. R. et al. Cigarette smoke-induced pulmonary inflammation, but not airway remodelling, is attenuated in chemokine receptor 5-deficient mice. Clin. Exp. Allergy 37, 1467-1479 (2007).

32. Bracke, K. R. et al. Cigarette smoke-induced pulmonary inflammation and emphysema are attenuated in CCR6-deficient mice. J. Immunol. 177, 4350-4359 (2006).

33. Vandesompele, J. et al. Accurate normalization of real-time quantitative RT-PCR data by geometric averaging of multiple internal control genes. Genome Biol. 3, RESEARCH0034 (2002).

34. De Smet, E. G. et al. Association of innate defense proteins BPIFA1 and BPIFB1 with disease severity in COPD. Int. J. Chron. Obstruct. Pulmon. Dis. 13, 11-27 (2018). 